Síntese - Rev. de Filosofia

v. 36 N. 114 (2009): 87-105

\title{
A UNIÃO DA ALMA COM O UM NA FILOSOFIA DE PLOTINO
}

(The union of the soul with the One in the philosophy of Plotinus)

Bernardo Guadalupe dos Santos Lins Brandão*

Resumo: Esse artigo é uma tentativa de análise da doutrina plotiniana da união mística da alma com o Um. Em primeiro lugar, mostramos que algumas palavras que foram interpretadas pela tradição como descrições da experiência mística, como êxtase e presença são, na verdade, usadas nas Enéadas para expressar algumas idéias metafísicas. Então, estudamos a relação entre a alma e o Intelecto durante a união mística: por que é necessário para a alma alcançar primeiro a união com o Intelecto para se unir ao Um? Depois disso, analisamos algumas imagens importantes: coincidência de centros, parentesco e semeIhança. Por fim, tentamos realizar uma interpretação da controversa questão da identidade entre a alma e o Um durante a união mística. Palavras-chave: Ploltino, alma, Um, união mística.

Abstract: This paper is an attempt to analyse the Plotinus' doctrine of the mystical union of the soul with the One. First, we show that some words that were interpreted by the tradition as descriptions of the mystical experience, like extasys and presence are used in the Enneads to express some metaphysical ideas. Then, we study the relation

\footnotetext{
* Professor de Filosofia da PUC-MG. Artigo submetido a avaliação no dia 13/08/2008 e aprovado para publicação no dia 15/10/2008.
} 
between soul and Intellect in the mystical union: why it is necessary to the soul achieve first the union with the Intellect to become united to the One? After that, we analyze some important images: coincidence of centers, relashionship and similarity. At last, we try to offer an interpretation to the controversial question about the identity between the soul and the One during the mystical union.

Keywords: Plotinus, soul, the One, mystical union.

$\mathrm{N}$ a Enéada VI, 9, após mostrar que o fundamento último da realidade não pode ser nem a Alma, nem o Intelecto, e que, por isso, está além detoda forma etoda atribuição, Plotino diz que não se pode conhecê lo nem pela ciência, nem pela intelecção, como no caso dos outros inteligíveis, mas através de uma presença superior à ciência, $k$ a t $a \backslash p$ a r o us i ąn episthmhj kreittona.

Esse modo de contemplação é expresso, em alguns momentos, através da metáfora da visão. Mas trata-se de uma outra forma de ver: êxtase e simplificação e um aumento de si, desejo de contato, repouso e consideração de uma harmonização. ${ }^{1}$

$\mathrm{Na}$ verdade, a contemplação do Um é um conhecimento unitivo: uma verdadeira união da alma com o princípio supremo da realidade. Por isso, em várias passagens, Plotino considerou apropriado empregar a metáfora do contato e do toque, utilizando vários termos: sunaf h\&(VI, , 9, 27), prosa ôt esqai (VI, 7, 40), qişein (VI, 9, 4, 27), etc. ${ }^{2}$

Vários desses termos se tornaram parte integrante do vocabulário da tradição mística ocidental, bem como de al gumas tradições mais orientais, como da Igreja ortodoxa [?] e, portanto, dão a impressão de ser suficientemente claros e capazes de transmitir uma idéia adequada, na medida em que isso é possível, da união com o Um. A final, todo aquele que conhece minimamente a literatura mística está familiarizado com termos como êxtase, compreendido como um arrebatamento fulminante, e presença, que parece traduzir um certo pressentimento mais ou menos irracional de que o divino está próximo.

As coisas, no entanto, não são tão simples. Estando nas origens do vocabulário da tradição mística, os termos das Enéadas não a pressupõem. Na verdade, baseiam-se na tradição religiosa e filosófica grega, especialmente a platônica e são dependentes da metafísica plotiniana.

${ }^{1}$ VI, 9, 11, 23. ễstasij kaiì aÀl wsij kaiì epidosij autou=kaiì eÃesij prol afhh kaii stasij kaiì perinohsij proj ef armoghh.

2 Sobre os termos usados nas Enéadas a respeito da união com o Um, ver ARNOU, Le Désir de Dieu, Roma: PUG, 1967, p. 235-241. 
Os dois exemplos acima citados ilustram bem a questão. "A palavra ekst asij ", como informa Dodds ${ }^{3}$, "tem uma vasta gama de aplicações na literatura grega": sua função primordial é significar uma mudança abrupta no estado mental. Assim, éusada para expressar estupefação, nos Evangelhos, ou a histeria e insanidade, em A ristóteles e em Hipócrates, bem como para denotar a possessão, seja divina ou diabólica.

O termo parece ter sido utilizado para descrever um estado místico, pela primeira vez, por Fílon de Alexandria. Em Quis rerum divinarum heres sit, 249, ele escreve:

Êxtase significa ou o furor delirante que provoca a loucura - sob o efeito da senilidade, da melancolia ou por uma outra razão análoga - ou a estupefação que experimentamos diante de acontecimentos ocorridos ao improviso - que então não esperávamos - ou ainda a calma da inteligência - se verdadeiramente é de sua natureza permanecer em repouso - ou, o mais nobre de tudo, a possessão e delírio de origem divina - pelos quais a raça profética é tomada. ${ }^{4}$

Ainda assim, como notaram estudiosos como Dodds $^{5}$ e Rist $^{6}$, não parece que Fílon esteja falando da mesma experiência que Plotino. Afinal, o êxtase profético é algo diverso de uma união mística inefável.

De fato, se encarada como uma descrição da experiência mística, oferece grandes problemas de interpretação. A final, como Plotino pode dizer em VI, 9, 11 que tal experiência é, ao mesmo tempo, ểstasij e st a\$ij ? E como seria tanto uma contemplação quieta do Um, mas, ao mesmo tempo, desejo de contato e consideração de harmonização? As coisas ficam mais simples tendo em vista a teoria da união com o Um: a experiência mística é ếstasij porque é uma saída do estado normal, no qual a alma não vive mais sua vida ligada ao sensível e ao pensamento discursivo, nem mesmo a vida noética do Intelecto, mas a vida do próprio fundamento de todas as coisas.

Já par ousi \& é um termo técnico do platonismo, denotando uma relação metafísica[?] entre duas realidades distintas, não um pressentimento qualquer. Aliás, a própria expressão "sentimento de presença", utilizada largamente nos estudos sobre mística, não me parece muito adequada para expressar

\footnotetext{
${ }^{3}$ DODDS, Pagan and Christian in an Age of Anxiety. Cambridge: Cambridge University Press, 1990, p. 70-72.

${ }^{4}$ Apud BRANDÃO, B. Pseudo Dionísio Areopagita: Sobre a Teologia Mística (tradução e notas). Kléos. Rio de J aneiro, v. 5-6, n. 5-6, julho de 2001, p. 158, nota 13.

${ }^{5}$ op. cit., p. 73.

${ }^{6}$ RIST, J . Eros and Psyche: studies in Plato, Plotinus and Origen. Toronto: University of Toronto Press, 1964.
} 
a contemplação plotiniana do Um, que não está apenas além da sensação, mas também do conhecimento intel ectual. ${ }^{7}$

\section{O Um e o Intelecto}

Como vimos, Plotino diz que, para se chegar à união com o Um, a alma deve antes se tornar Intelecto e se subordinar ao Intelecto. Ou seja, ela deve se unir à totalidade do mundo inteligível e contemplá-lo. Mas isso não é o bastante. $\mathrm{Na}$ Enéada $\mathrm{VI}$, 9, ele assevera que o Um é contemplado com o Intelecto puro e com o que existe de primeiro no Intelecto. ${ }^{8}$ Esse texto pode ser aproximado de $V, 5,8$, no qual está escrito que o Intelecto vêo Um com aquilo de si mesmo que não élntelecto. A mesma idéia também aparece em III, 8:

- O que então é o que traremos, dispondo o intelecto?

- De fato, é necessário que o Intelecto como que se retire para trás e, abandonando a si mesmo, como que se entregue à sua parte anterior, tendo duas frentes, e, com relação a essas coisas, se quiser ver aquilo, que não seja totalmente Intelecto9.

Mas o que é essa parte superior do Intelecto com a qual é possível ver o Um? E ainda, qual a relação da contemplação do primeiro princípio, realizada pela alma, com a que é feita pelo Intelecto? É o que Plotino esclarece em VI, 7:

Assim, pois, o Intelecto tem uma potência para o inteligir, com a qual vê as coisas que estão nele, e uma outra, uma outra, com a qual vê as coisas que estão além dele, em uma certa apreensão e contato, pela qual, primeiro, somente vê e, em seguida, vendo, tem Intelecto e é um. Aquela é a contemplação do Intelecto sensato, mas a outra é o Intelecto que ama, quando se torna insensato, embriagado de néctar: amando então, tendose simplificado, chega ao bem estar na saciedade. E, para ele, embriagarse daquela embriaguez é melhor que estar na gravidade mais venerável.

- Mas aquele Intelecto vê em parte ora uns, ora outros?

- Não. O discurso que ensina os coloca no devir, mas o Intelecto tem sempre o inteligir e sempre o não inteligir, mas o ver aquele de outro

\footnotetext{
${ }^{7}$ Causa-me assim estranhamento que um estudioso tão cuidadoso como Hadot afirme, em seu comentário a VI, 7 (HADOT, P. Traité 38. Paris: Ed. du Cerf, 1987, p. 59-60) que uma das características da experiência mística de Plotino seja um sentimento de presença.

${ }^{8} \mathrm{VI}, 9,3$.

9 III, 8, 9, 30-33. Ti $i$ ouß̊ e\$tin ók komioumeqa noun parasthsamenoi; toh noun oîn eif toupisw ahaxwreih kaì oîn éutoh af enta toil eif oñisqen autou=amf istomon oñta, kakeiha, ei ${ }^{1}$ eqel oi ekeiho of a nta noun eiåai.
} 
modo. Pois, vendo aquele, tem descendência e toma consciência de que eles surgiram e que estão nele. $E$, quando os vê, diz-se que intelige. $M a s$, quando vê àquele, o faz com a potência na qual está na iminência de inteligir. ${ }^{10}$

Existem, desse modo, duas potências no Intelecto: uma com a qual ele vêas formas inteligíveis em seu interior - a sua própria intelecção -, e uma outra com a qual contempla o Um. Plotino chama esta última potência de Intelecto amante, caracterizando-a com a mesma imagem, retirada do Banquete, que se emprega na descrição da união da alma com o Intelecto, a embriaguez do néctar. O filósofo também esclarece que, ao contrário da alma encarnada, sujeita ao devir, mas capaz contemplar o Um, essa visão não se alterna com outros tipos de experiência no Intelecto: ele possui os dois tipos de consciência simultaneamente, já que está na eternidade.

O Intelecto amanteétambém situado com relação ao que intelige: novamente utilizando uma descrição temporal para dar a entender realidades metafísicas, Plotino declara que, inicialmente, o Intel ecto é visão pura. Em seguida, tem descendência, ou seja, as formas aparecem, e ele é capaz de inteligir. A contemplação do Um é feita com essa visão pura, essa potência pela qual o Intelecto ainda não intelige, mas está na iminência de o fazer.

Nesse contexto, éútil considerar brevemente a gênese do Intelecto. Eis o que Plotino diz a respeito em $\mathrm{V}, 2$ :

Pois, sendo perfeito (o Um) por nada procurar, nem ter, nem necessitar, é como se tivesse transbordado e de sua superabundância fez um outro: este, surgindo, voltou-se para aquele, foi preenchido e, olhando para ele, tornou-se este Intelecto. $\mathrm{E}$, por um lado, o seu deter-se junto àquele fez o ente. Por outro Iado, a contemplação daquele fez o Intelecto. ${ }^{11}$

\footnotetext{
${ }^{10} \mathrm{VI}, 7,35$. Kaì toh noun toigun thh men eãein duhamin eif tol noeíh, vÂ tal en aut \% $\frac{1 / 2}{2} b l$ epei, thh del $v \hat{A}$ tal epekeina autou= epibol v=tini kaii

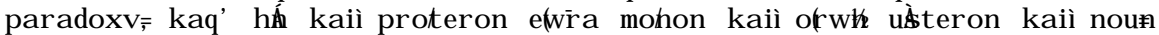

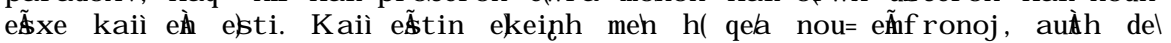

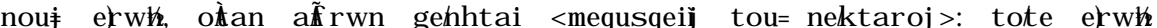
ginetai aplwqeij eif eupaqeian t\%1/2kot \%: kail eâtin aut $\% \frac{1}{2}$ mequein beltion häsemnotet\% eiåai toiauthj meghj. P aral metoj del ol nouj ekeihoj aÃla,

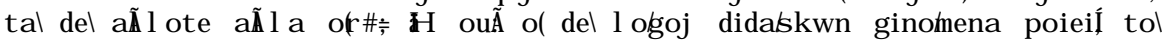

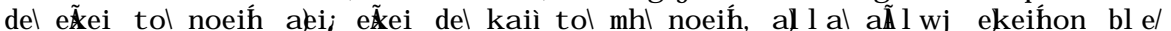

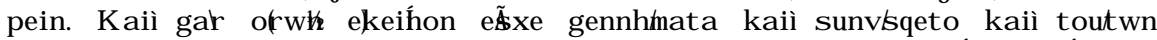
genomehwn kaì ehontwn: kaii tauka men ofwhr l egetai noeih́, ekeiho del $\checkmark \hat{A}$ duna mei eñel I e noeíh.

${ }_{11} \mathrm{~V}, 2,1,7-9.0 \ddot{A}$ gat tel eion $t \% \frac{1}{2}$ mhdeh zhteih mhdel ex̃ein mhdel deí́sqai oiên upererruh kaiì tol uperpl haej autou=pepoibken ẫlo: tol del genol menon eif autol epestrafh kaiì eplhrwāh kaiì egeneto prol autol bl epon kaì nouj ouÂoj. Kail h( meh prol ekeiho stasij autou=tol ö̈ epoihsen, he del prol autol qea toh noun.
} 
Em sua superabundância, o Um transbordou e produziu algo diverso de si. Esse algo diverso se voltou para a sua origem e, contemplando-a, tornouse Intelecto. Existem aqui três etapas: o transbordar do Um que produz algo diverso dele, o voltar-se ao Um desse al go que foi produzido ea contemplação. $\mathrm{Na}$ primeira etapa, o que foi produzido é algo indeterminado e informe. Plotino o chama de "alteridade" e "matéria" inteligível12. Quando a alteridade se detém e se volta para o Um, ela é determinada e, então, aparece o Ente. Quando este contempla o Um, surgem as formas inteligíveis.

Como acontece em vários dos aspectos da filosofia plotiniana, não se pode esperar que todos os textos que falem da gênese do Intelecto apresentem esse mesmo esquema e a mesma nomenclatura. Tudo depende do propósito de cada texto. Assim, em V , 1, 4, mostrando que o Ente e o Intelecto, as duas partes do Intelecto total, são interdependentes, Plotino afirma que, ao inteligir, o Intelecto faz subsistir o Ente e que este, ao ser inteligido, dá ao Intelecto o inteligir. Com isso, o filósofo dá a impressão de que é o Intelecto, e não o Ente a realidade primaria da segunda hipóstase. ${ }^{13}$

Mas a problemática relação entre Ente e Intelecto não é determinante para o presente propósito e, portanto, não há necessidade de aprofundar essa discussão. O importante aqui é notar que a potência com a qual a segunda hipóstase contempla o Um já não é apenas a matéria inteligível - e assim, já é al go determinado -, mas tampouco é o Intelecto que vê em si todas as formas inteligíveis. É um estado intermediário, chamado em V, 2 de Ente. Plotino fala mais desse estado e de sua relação com o surgimento das formas inteligíveis em VI, 7:

- Então, quando olhou o Bem, inteligiu aquele "um" como muitas coisas e, ainda que fosse um, inteligiu-o como muitas coisas, dividindo-o por não poder inteligir o todo junto?

- Mas é que, olhando aquele, não era ainda Intelecto, mas via de um modo não intelectivo. $\mathrm{Na}$ verdade, deve ser dito que nem ao menos viu o Um jamais, mas vivia junto dele, estava suspenso nele e se voltava para ele. Então, esse movimento, plenificado por mover-se ali, ao redor do Um, plenificou-o e, assim, não mais era apenas movimento, mas movimento saturado e pleno. Em seguida, tornou-se todas as coisas e soube disso através da consciência de si. Então, já era Intelecto, plenificado por ter o que devia ver e vendo essas coisas com a luz que vem daquele que deu essas coisas e que fez isso acontecer. ${ }^{14}$

12 II, 4, 5, 25-39

${ }^{13} \mathrm{~V}, 1,4,26-29$.

${ }_{14} \mathrm{VI}, 7,16,11-23$. A ra, oAe ewra prol tol agaqoh, ehoei wj pollal tol eÁ ekeiho kaiì eÁ ö̈ autol ehoei autoh pollal merizwn autoh par' aut $\% \frac{12}{2}$

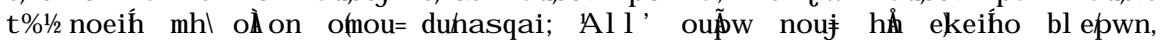
all' eâl epen ahohtwj. G fatebn wj oudel ewria pwpote, all' eâh meh prof autol kaiì ahhthto autou=kaiì epestrapto prof autol h(dhl kighsij 
Nessa passagem, é a própria contemplação do Um que, ao plenificar e saturar o Intelecto com sua potência, dá origem às formas inteligíveis. Outros textos determinam ainda mais essa contemplação do Um: em V, 3, a contemplação anterior às formas é "somente desejo evisão sem impressão" 15; já em V , 6, Plotino diz que o desejo de ver já é visão; também declara que o pensamento é um movimento em direção ao Bem por desejo do Bem afinal, é em virtude de sua contemplação que surgiram as formas inteligíveis ${ }^{16}$.

Interpretando $\mathrm{VI}, 7,16$, Reale diz que o Intelecto não pensa o Um, mas a si mesmo, pleno e fecundado pelo Um ${ }^{17}$ Levando essa interpretação às últimas consequências, seria possível concluir que não existe propriamente uma contemplação da realidade suprema, mas apenas de sua potência no interior do Intelecto ${ }^{18}$. Não me parece, entretanto, ser esse o caso. Na passagem em questão, afirma-se existir uma visão não intel ectiva do Um. Se em seguida Plotino se corrige e diz que o Intelecto nunca o viu, é porque a metáfora da visão não é adequada para expressar essa relação. Como tivemos a ocasião de notar, de fato, ela é constantemente corrigida. Assim, Plotino fala que o Intelecto não via propriamente o Um, mas estava junto dele, voltava-se para ele e estava suspenso nele. A imagem do Intelecto suspenso no Um aparece também em VI, 8, ligada à metáfora do toque: "está fora dele (do Um), como em um círculo, tocando-o e suspenso nele, tudo o que érazão e Intelecto"19. Ora, o verbo ef a ât esqai e seus derivados são recorrentes nas descrições da experiência mística do Um nas Enéadas. ${ }^{20}$

A interpretação de que o Intelecto amante é a fase anterior ao surgimento das idéias foi defendida por vários críticos. ${ }^{21}$ Bussanich ${ }^{22}$, no entanto, contestou-a, afirmando existir três modos de vida do Intelecto: a nascente,

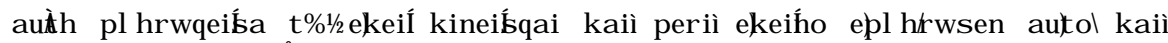
ouketi kinhsij ha mohon, allal kinhsij diakorhl kail plhthj: eth $=$ del

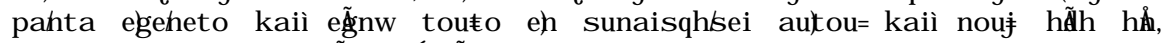

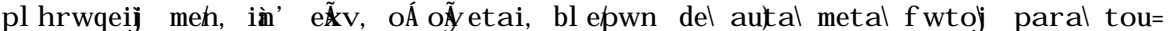
dohtoj ekeiha kaiì touko komizomenoj.

$15 \mathrm{~V}, 3,11,11$.

prol del toutou eÃesij mohon kaiì ałuphtoj oñ ij. Impressão aqui entendida como túpos.

${ }^{16} \mathrm{~V}, 6,5,5-10$.

17 REALE, G. História da Filosofia Antiga, IV, São Paulo: Loyola, 1994, p. 461

18 Reale, no entanto, tendo usado a passagem apenas para tratar da gênese das formas no interior do Intelecto, não escreveu sobre as conseqüências de tal interpretação para a teoria da experiência mística.

${ }_{19} \mathrm{VI}, 8,18,4-5$. tol d' eãw autou= oî̂n kukl\% ef aptomenon autou=kaì exhrthmehon paA ó I ogoj kaiì nouj.

${ }^{20}$ ARNOU, Le Désir de Dieu, p. 237-238.

${ }^{21}$ Entre eles Hadot, O'Daly e Trouillard.

${ }^{22}$ BUSSANICH, J. The One and Its Relation to Intellect in Plotinus. Leiden: Brill, 1988, p. 231-236. 
ou seja, aquele que ainda não possui as formas; a atualizada, que intelige as formas; e a hiperôntica, que ama e contempla o Um. Segundo ele, nas passagens a respeito do Intel ecto nascente, Plotino nunca fala de êxtase ou amor, típicos do Intelecto hiperôntico, mas de movimento e desejo, que contrariam a noção de repouso e a imobilidade características da união com - Um. Além disso, para ele, a união da alma com o primeiro princípio não é facilmente conciliável com a idéia de uma "visão sem impressão".

Mas sua interpretação não me parece ser satisfatória. Isso porque existem algumas passagens que sugerem a identificação entre o Intelecto nascente e o hiperôntico. Uma delas é a própria VI, 7, 35, em dois momentos. Em primeiro lugar, quando Plotino diz que o Intelecto possui uma potência de ver o que está além - ou seja, de contemplar o Um -, que é "uma certa apreensão e contato, pelo qual, primeiro, somente vê e, em seguida, vendo, tem Intelecto e é um". Em segundo lugar, logo no fim da passagem que fala das duas potências está escrito: "mas quando vê aquele, faz isso com a potência na qual está na iminência de inteligir". Ora, enquanto o primeiro trecho trata da visão pura anterior à intelecção, bem como de uma apreensão e de um contato, o segundo fala da iminência da intelecção. Em ambos os textos, o nascimento do Intelecto é ligado à contemplação do Um.

Além disso, os argumentos de Bussanich não me parecem muito fortes. É certo que Plotino fala do movimento e do desejo do Intelecto nascente em direção ao Um. Entretanto, também fala, em III, 8, que o Intel ecto está sempre a desejar o Um, mas que está também sempre alcançando o que deseja23, sugerindo que o repouso pode ser conciliado com o movimento do desejo. Além disso, as passagens que Bussanich cita não tratam do repouso do Intelecto, mas do repouso da alma, dando a entender que a alma deve interromper suas atividades relacionadas com o mundo sensível e a intelecção para experimentar o Um. Por sua vez, também não me parece extraordinário que Plotino, em muitas passagens, não declare que o Intelecto nascente seja também amante. Na verdade, são pouquíssimas as passagens que dizem respeito ao amor do Intelecto pelo Um. Bem mais comuns são as referências ao amor da alma.

Mas, qual a relação da alma com a experiência mística do Intelecto? É que, unindo-se ao Intelecto, ela participa de sua vida interior. Assim, em primeiro lugar, tem a experiência da totalidade do inteligível, participando da potência intelectual "sensata". Pode acontecer, entretanto, que ela também participe da potência "insensata". Quando isso acontece, ela tem a mesma experiência do Um que o Intelecto possui. É o que Plotino afirma na continuação da já mencionada passagem de VI, 7, 35:

23 III, 8, 11, 24. 
E a alma está, como que confundida e desfigurada, permanecendo o intelecto que está nela, ou melhor, o seu intelecto vê primeiro, a contemplação também vai até ela e os dois se tornam um. O Bem, por sua vez, estendido sobre eles e harmonizado com a constituição de ambos, correndo e unindo os dois, está sobre eles, dando-lhes uma sensação e contemplação bemaventurada, levantando-os de tal modo que não estão em um lugar, nem em outras coisas, nas quais, por natureza uma coisa está em outra, pois ele próprio não está em algum lugar. O lugar inteligível está nele, mas ele próprio não está em outro. ${ }^{24}$

A alma, que durante a mística intelectual está confundida com o Intelecto e como que desfigurada, já que, situada totalmente no inteligível, não realiza suas funções de relação com o mundo sensível, pode ter a experiência do Um. E isso acontece da seguinte maneira: o Intel ecto nascente é aquele que vê em primeiro lugar o Um. Unidas ao Intelecto total, as formas inteligíveis também participam dessa contemplação. A alma, por sua vez, também pode ter essa experiência quando é semel hante a um intelecto e, dessa maneira, está ligada ao Intelecto total.

\section{O Um e a Alma: Coincidência de Centros}

Na Enéada VI, 9, 8, a união da alma com o Um é abordada em uma outra perspectiva: como coincidência de centros e semel hança. Juntamente com VI, 7, 35, este é um dos textos mais importantes das Enéadas sobre a teoria da união mística com o Um. No entanto, é uma passagem difícil, na qual estão subentendidos uma série de pontos fundamentais. Por isso, deve ser analisada mais detidamente. Comecemos pelo início do capítulo:

Se então a alma conhece a si mesma em outro momento e sabe que seu movimento não é uma reta - a não ser quando se rompe -, mas que seu movimento segundo a natureza é tal como o movimento em círculo ao redor de algo que não é exterior, mas ao redor de um centro: o centro a partir do qual existe o círculo - a alma se moverá ao redor dele, a partir do qual existe, e, com ele, se suspenderá, levando-se a si mesma a este mesmo centro, que era necessário a todas as almas, mas ao qual só as dos deuses se dirigem sempre: por dirigirem-se a ele é que são deuses, pois é

\footnotetext{
${ }^{24} \mathrm{VI}, 7,35 . \quad H$ del y uxhl oîn sugxelas kaiì af anisasa mehonta toh eh

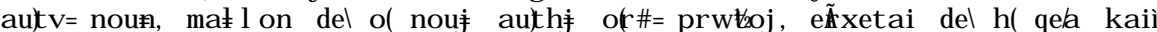
eif authh kaiì tal dub eÁ ginetai. Ektaqeh del tol agaqoh ep' autoij kail sunarmosqen $t v=a m f o t e r w n$ sustakei epidramon kaii ehw bran tal dup eãestin autoij <makarian> didoul aiãghsin kaiì <qean>, tosoukon a Ãaj,

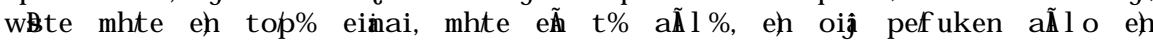

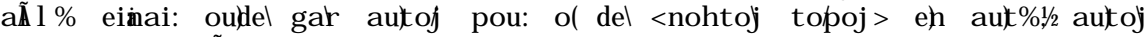
del ouk en ẫl \%.
} 
Deus o que se junta àquele - e o que se afastam para longe é o homem comum e a fera. 25

Em primeiro lugar: qual é esse "outro momento" em que a alma conhece a si mesma e descobre que seu movimento não é uma reta? Na passagem imediatamente anterior ${ }^{26}$, Plotino diz que o Um não está fora de ninguém, mas presente a todos, mesmo que não o sai bam; isso porque aqueles que não sabem da presença do Um fogem dele e de si mesmos, assim como uma criança que, tomada pela loucura, não reconhece seu pai. Levando em conta esse texto, é fácil perceber que o outro momento em que a alma se conhece é aquele em que ela não foge de sua origem e de si mesma ${ }^{27}$.

Em seguida, éimportante esclarecer a natureza do movimento da alma. Está escrito em II, 2 que a alma possui um movimento não espacial, voltado a si mesmo, autoconsciente[?], autointelectivo evital, que, metaforicamente, pode ser considerado circular ${ }^{28}$.

Mas o que será então essa possibilidade de rompimento do movimento circular da alma? Não existem outras passagens de VI, 9 a esse respeito e o próprio Plotino não parece estar preocupado em esclarecer essa questão. Isso, assim creio, porque ele esperava que seus leitores estivessem familiarizados com o texto de Timeu 43, no qual Platão escreve que o movimento da alma é rompido pela força das sensações ${ }^{29}$. A questão é iluminada também por II, 2, 14-19, onde Plotino declara que o corpo tem a tendência de se mover retilineamente. Ou seja, quando a alma não está fugindo de si mesma e de seu princípio - e então está apta a se conhecer -, ela possui um movimento reflexivo como que circular. No entanto, quando se submete aos apegos corporais e, assim, foge de si mesma, voltando-se para o exterior, esse movimento se rompe e ela é arrastada pel o poder das sensações.

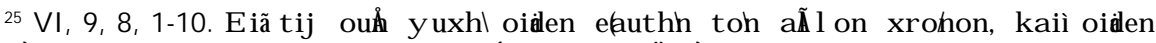

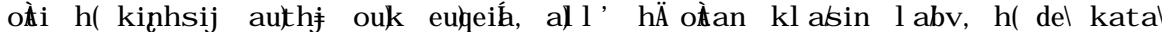
fusin kinhsij oià h( en kukl\% pericti ouk eãw, all al periì kentron, tol del kehtron af' ouÂAo( kukloj, kinhsetai periì touko, af' oûA e\$ti, kaiì toutou aharthsetai sumf etousa eluthn prol tol autol prol oÁ exrha meh pasaj, ferontai del ai, qew br a ei i prol oÁferomenai qeoi $i$ eisi. Qeol gar tol ekein\% sunhmmenon, tol del porrw afistamenon a Ãgrwoj ol pol ul kaii qhrien.

${ }_{26} \mathrm{VI}, 9,7,27-34$

27 Essa interpretação, seguida por Hadot e Meijer em seus comentários, não é, no entanto, unânime. Como nota Meijer (MEIJ ER, P. Plotinus on the Good or the One (Enneads VI, 9): an analytical commentary. Amsterdã: Gieben, 1992, p. 229), Bréhier não traduziu a expressão ton a Ãl on xrohon; MacKenna a traduziu por "its history"; Cilento por "in qualche alteria stagione di vita"; etc. Não vejo, no entanto, nenhum bom argumento para que o texto anterior não seja considerado como a chave para essa questão.

${ }^{28} \mathrm{II}, 2,1$.

29 MEIJ ER, op. cit., p. 229, n. 661.
} 
O texto continua, falando agora do centro da alma, a partir do qual ela existe. Com esse centro, a alma pode se ligar e se suspender ao centro necessário a todas as almas, ao qual, entretanto, somente os deuses se dirigem sempre. Mas, que centros são esses? $\mathrm{E}$ ainda, o centro da alma é a mesma coisa que o centro de todas as coisas? Continuemos a análise do texto:

Assim, aquilo que é como que o centro da alma é o que buscamos? $\mathrm{Na}$ verdade, é necessário considerar outro, para o qual todas as coisas que são como centros coincidem. É por analogia que falamos de centro do círculo ${ }^{30}$. Pois a alma não é um círculo como a figura, mas nela e ao redor dela existe a natureza original, a partir da qual ela existe. Além disso, as almas estão todas separadas. ${ }^{31}$

O centro da alma é aquilo que é buscado, ou seja, o próprio Um? A resposta é negativa: o centro de todas as coisas não éo centro da alma. Mas, de algum modo, eles coincidem. De que maneira? Eis um ponto chave para a compreensão da teoria da união da alma com o Um.

Plotino também nos lembra que a idéia do centro de um círculo éusada aqui como uma analogia. Afinal, a alma é uma realidade imaterial, não uma figura. E, por isso, o que seria como que o seu centro, a partir do qual ela existe, está nela, ou seja, em seu interior, mas também ao redor dela32: a metáfora do centro e do círculo nem sempre é conveniente. Além do mais, a imagem do centro é apenas uma analogia porque as almas "estão todas separadas" do corpo $0^{33}$ quando conhecem a si mesmas e possuem o movimento circular - o que não é o caso do homem apegado ao sensível, cuja situação é descrita na seqüência do texto.

\footnotetext{
30 Como Meijer, p. 232-233 e contra Harder e Schwyzer, considero que, das três primeiras frases desta passagem, apenas a primeira é uma interrogação. Ambas as posturas, no entanto, podem ser conciliadas com a interpretação do texto que aqui apresento.

${ }_{31} \mathrm{VI}, 8,10-16$. Tol ouß thj y uxhj oiên kehtron touko/ ełti tol zhtoumenon:

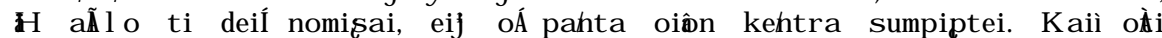
ahalogi\# tol kehtron tou\#e tou=kuklou. Oublel gar ouAw kukloj hl y uxh wj tol sxhma, all' oni en autvakaiì periì authh h( a)xaia fusij, kail oni

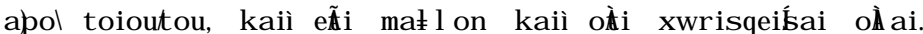

32 Para Hadot, na sua tradução comentada de VI, 9, (HADOT, P. Traité 9. Paris: Ed. du Cerf, 1994), o per iì não deve ser lido aqui como "ao redor", mas como "a respeito de", pois não faz sentido que a natureza original esteja ao redor da alma. Não concordo com essa posição. Creio que o que Plotino quer dizer aqui é precisamente isto: que a natureza primordial da alma pode ser chamada de centro apenas por analogia, pois ela está não apenas dentro da alma, mas em toda a alma, ou seja, ao redor dela. Meijer, p. 236, também não vê nenhum problema em ser possível dizer que o centro da alma esteja ao redor dela.

33 MEIJ ER, p. 235.
} 
Devemos agora nos perguntar: o que é essa natureza original da alma, que é como que seu centro, a partir da qual ela existe? Investigando a questão, Meijer propõe três possibilidades:

1. É a hipóstase Alma, da qual todas as al mas participam e que, assim, está ao redor de todas elas.

2. Em paralelo com Timeu 90d, éa natureza original da alma individual. 3. $\mathrm{OUm}$.

Meijer diz que, no fim, opta pela opção três, talvez em conjunção com a dois. Entretanto, parece-me que Plotino quer dizer aqui que essa natureza original é o centro da alma. Se esse é o caso, como o centro da alma não é o centro de todas as coisas, ele não pode ser o Um.

A opção dois me parece mais plausível, não apenas por causa do paralelo com o Timeu, mas também pela confirmação de outros textos platônicos, bem como de outras passagens das Enéadas. Como mostra Armstrong em sua tradução do texto ${ }^{34}$, a idéia de uma natureza original da alma aparece também no Banquete 192 e 9, na República 611d e, nas Enéadas, em VI, 5 , 1, 6, II, 3, 8, 14 e em IV , 7,9, 28.35 A natureza primordial da alma, assim me parece, não é outra que a sua parte que pode se unir ao Intelecto. As outras partes, por sua vez, são as potências sensitiva e vegetativa ${ }^{36}$.

Em III, 8, Plotino diz que as partes inferiores participam das superiores, pois procedem delas, e que existe uma atividade que se propaga por todas elas. É por isso que se pode dizer que sua natureza primeira está dentro eao seu redor da alma: está dentro porque é de onde as outras partes surgem; e ao redor porque a atividade que existe em plenitude nel a também se propaga pelas demais partes:

Mas agora, já que uma parte de nós é dominada pelo corpo, como se alguém tivesse os pés na água, mas com o resto do corpo a sobrepassasse, elevando-se com a parte não submersa do corpo, assim coincidimos o centro de nós mesmos com o que se poderia chamar de centro de todas as coisas, assim como os centros dos grandes círculos coincidem com o da esfera que os rodeia, repousando. ${ }^{37}$

É com a parte que não se liga ao sensível que podemos coincidir o centro da alma com o centro de todas as coisas, isto é, com o Um. Plotino compara

\footnotetext{
${ }^{34}$ p. 330, apud HADOT, na sua tradução comentada, p. 100, n. 155.

35 Deve-se incluir também II, 3, 15, 17 junto com os outros textos.

$36 \mathrm{II}, 2,3$.

${ }^{37} \mathrm{VI}, 9,8,16-22$. N un del epeiì met oj $h(m w \not h r ~ k a t e k$ et ai upol tou=sw matoj, oiên

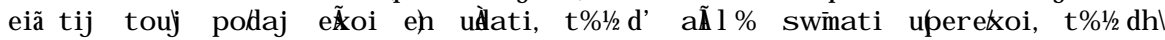
mhl baptisqehti t\% $\frac{12 / 2}{s}$ wmati uperarantej, tout \% sunaptomen katal tol

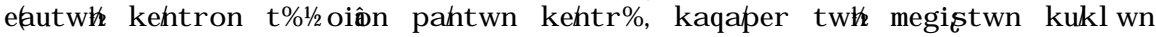
tal kentra t\% $\frac{12}{2}$ thj sfaicaj thj periexoushj kentr\%, ahapaumenoi.
} 
essa coincidência de centros com a coincidência do centro de um círculo com o centro da esfera, ou seja, o centro de todos os círculos. No entanto, essa noção de coincidência, devemos nos lembrar, é apenas uma imagem válida até certo ponto:

Se então fossem corporais, não círculos espirituais, seus centros coincidiriam localmente e, onde quer que estivesse localizado o centro, ao redor dele estariam. Mas, já que estas são almas inteligíveis e aquele está além do Intelecto, por potências diferentes, da maneira que é natural ao que intelige coincidir com o que é inteligido, deve-se pensar que surge o contado, e que é ainda maior, já que o que intelige está presente pela semelhança e identidade e coincide por ser parente, nada os separando. Pois nos corpos, os corpos impedem a comunhão de uns com os outros, mas os incorpóreos não são separados pelos corpos. Nem há um lugar que os separe uns dos outros, mas a alteridade e a diferença. Assim, quando a alteridade não está presente, as coisas que não são outras estão presentes. E aquele, não tendo alteridade, sempre está presente, enquanto nós, quando não a temos. E aquele não aspira a nós, de modo a estar a nossa volta, mas nós aspiramos a ele, de modo a nós estarmos em volta dele. ${ }^{38}$

Os conceitos que pressupõem o espaço se aplicam apenas metaforicamente aos seres imateriais. É o que ocorre no presente caso: como os centros aqui em questão não são centros de figuras, mas da alma e de todas as coisas, eles não podem coincidir localmente. Como se dá, então, a coincidência? Pela semelhança, pela identidade e pelo parentesco. Desse modo, para a correta compreensão da imagem plotiniana da coincidência de centros, devemos analisar mais detidamente esses termos.

\section{Parentesco e Semelhança}

A doutrina de que a união da alma com o Um se faz pela semelhança e o parentesco também aparece em $\mathrm{VI}, 9$, 4:

Pois aquele $(O \mathrm{Um})$ não está ausente de nada, estando junto de todas as coisas, de modo a, estando presente, não estar presente a não ser aos que

\footnotetext{
${ }^{38} \mathrm{VI}, 9,8,22-36$. E i $\mathrm{i}^{1}$ meh ouß swmatikoiì han, ou) y uxikoiì kukloi, topikw a $\mathrm{A}$ t $\% \frac{1}{2} \mathrm{k}$ entr\% sunhoton kai pou keimenou tou=kentrou periì autol a hón: epeiì del autaicte ai, y uxaiì nohtaic uper nouf te ekeiho, dunamesin ẫl aij, vÂpefuke tol nooü proj tol katanooumenon sunaptein, oihtebn thh sunafhh ginesqai kaii pleohwj tol nooun pareihai omoiothti kai tautothti kaii sunaptein t\% $\frac{12}{2}$ suggeneil oudenol dieiggontoj. Swmasi men gak swmata kwl uktai koinwneih all h/oij, tal del a\$w mata swmasin ou) dieiggetai: oud' af esthke toigun allh/wn top\%, eterothti del kaiì diafor \#=

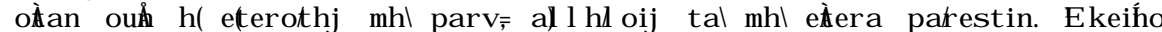

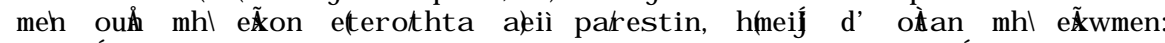
kakeiho meh h(mw br ouk ef ictai, wote periì hmaj eiåa, hmeij del ekeinou, wote hmeil periì ekeiho.
} 
podem e estão preparados para o receber, de modo a se harmonizar e, de alguma maneira, a estar em contato e tocá-lo pela semelhança e pela potência que há neles, parente do que vem dele; quando assim for, como era quando veio a partir dele, já poderá ver, de modo que aquele possa ser naturalmente contemplado. ${ }^{39}$

Nesse texto, Plotino diz que podemos al cançar a união com o Um por uma potência queé parente do que vem dele (do que vem dele, éimportantenotar, e não propriamente dele) e que ela existe desde os princípios da geração das coisas - o queé entendido pelo trecho "como era quando veio a partir dele". A partir disso, é possível supor que essa potência é o Intelecto amante. A final, é através dele que a alma se liga ao princípio supremo.

Quanto à semelhança: segundo Plotino, os corpos não podem entrar em comunhão uns com os outros por sua própria natureza corpórea. Esse não é o caso dos seres imateriais, distintos uns dos outros pela alteridade. Quando dois seres imateriais não são diferentes, em nenhum aspecto, um do outro, eles se unem, já que não há matéria ou espaço que os separem. Como unidade absoluta, o Um não possui nenhuma alteridade. Assim, para que seja possível a união com ele, é necessário suprimir toda a alteridade existente na alma.

Como fazer isso? Em primeiro lugar, seguindo $\mathrm{V}, 3^{40}$, a alma deve suprimir a alteridade decorrente de sua ligação com o sensível, ou seja, desapegarse do corpo e, em seguida, da imagem da alma que se liga ao corpo, bem como das sensações, desejos, iras e demais paixões. Isso se faz através da purificação, permitindo, ao menos por alguns momentos nesta vida, que toda a atividade da alma esteja concentrada em sua parte racional.

Já sabemos quea alma purificada do sensível é capaz de se unir ao Intelecto. Isso, no entanto, não é o bastante para a união com o Um. Por menos alteridade que exista no Intelecto e por mais unidade que exista entre $o$ pensamento e o que é pensado em seu interior, ele ainda possui alteridade. Afinal, se não existisse alteridade, as formas não poderiam se distinguir umas das outras. Mesmo que no Intelecto o conhecimento seja interior e, portanto, uno, ainda assim, de algum modo, persiste a dualidade entre sujeito e objeto. Para que exista conhecimento, é necessária uma relação entre aquele que pensa e aquilo que é pensado, mesmo quando o objeto é o próprio sujeito. No pensamento, diz Plotino, deve existir sempre e necessariamente a alteridade e a identidade ${ }^{41}$.

\footnotetext{
39 VI, 9, 4. ou)gar dhI a p̃estin oudenol ekeiho kaiì pahtwn del wate parwä mh pareihai all' hätoij dekesqai dunamehoij kaiì pareskeuasmehoij, wote

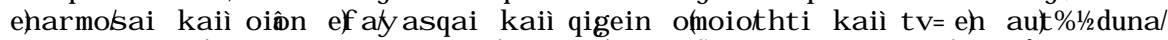

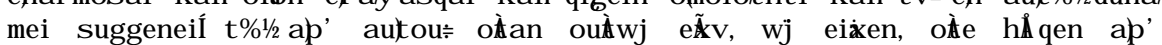
autou= häh duhatai ideih wj pefuken ekeihoj qeatol eiåai

$40 \mathrm{~V}, 3,9,1-7$.

${ }^{41} \mathrm{~V}, 3,10,25$.
} 
Assim, para que a alma possa se tornar semelhante ao Um, ela deve não apenas suprimir a ligação ao sensível, mas também a própria alteridade inteligível. Em suma, ela deve transcender o próprio mundo das formas:

Já que também a alma, quando recebe dele um amor intenso, depõe toda a forma que tinha, depõe também qualquer forma de ordem inteligível que estava nela. Pois não é possível, tendo e fazendo alguma outra coisa, nem ver nem se adequar a ele: não se deve ter em mãos nem algo mau, nem também algo bom, nem outra coisa, para que receba só o Só. ${ }^{42}$

É essa a razão de ser do famoso adágio plotiniano afle e pat a, suprime tudo $^{43}$. Quando se suprime tudo, não existe mais alteridade, apenas identidade. A alma se torna, assim, semelhante ao Um. Sem a presença da alteridade, não existindo nada mais que os separe, eles podem se unir.

Durante a união, a alma experimenta a vida interior do princípio supremo: assim como ela não contempla o Intelecto como um objeto exterior, mas como algo que ela se tornou, a alma pode ver o Um porque ela mesma se tornou una e pura identidade. Para ser mais claro: em vários momentos ${ }^{44}$, Plotino afirma que o Um não pensa. Não porque seja irracional e esteja abaixo do pensamento, mas porque sua consciência, sendo pura identidade e não possuindo nenhuma alteridade, está acima do pensamento. É uma supraconsciência[?], "uma certa apreensão simples, nele, em direção a si mesmo" 45 , al go como um movimento simples e idêntico, como um contato que não tem nada de intel ectivo ${ }^{46}$.

Ora, essas caracterizações empregam os mesmos termos utilizados na união mística com o Um experimentada pela alma e pelo Intelecto. Como vimos, a autoconsciência[?] do Um, segundo Plotino, não é um pensamento de si, mas al go como um um toque, epaf h\&Ora, essa palavra também aparece em VI, 7, 36 e em VI, 9, 7 para fal ar da experiência mística da alma ${ }^{47}$. Já em VI, 7, 39, 1-2, Plotino usa epibol h\& que significa apreensão ou intuição. 0 mesmo termo aparece em VI, 7, 35, 21-22, ligado ao Intel ecto amante: ele vê o que está alem de si por uma certa apreensão e contato, epibol h⿻三 ini kaiì paradoxh= É certo que esses termos aparecem em outros contextos nas

\footnotetext{
$42 \mathrm{VI}, 7,34,2-7$

${ }^{43} \mathrm{~V}, 3,17,37-38$

${ }^{44} \mathrm{~V}, 3,10 ; \mathrm{V}, 6 ; \mathrm{VI}, 7,37-42 ; \mathrm{VI}, 9,6$.

$45 \mathrm{VI}, 7,39,1-2.6 .7$. 'apl h=tij epibol hI aut\%1/2prof autoh.

${ }^{46} \mathrm{VI}, 7,39,18-19$. eip̃er tol del aploun kaiì tol autol pan oîn kinhma, ei ${ }^{1}$ toioukon eín oîn epafhl ouldeh noeroh eãei.

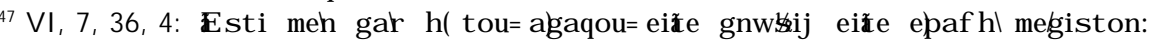
"pois o conhecimento ou toque do Bem é o maior".

VI, 9, 7, 25: tou= qeiqu epaf v=eif nomwn plhroumenoj qesin - (a respeito de Minos, que, para Plotino, teve a experiência do Bem): "plenificando o estabelecimento das leis pelo toque do divino".
} 
Enéadas. @i bol h\$por exemplo, éligado à diánoia em II, 4, 10, 3 eao sensível em IV , 6, 3, 73. ${ }^{48}$ Do mesmo modo, fala-se de epaf h\&até mesmo com relação à aplicação de feitiços, em IV , 4, 40, 11. Assim, se apenas uma das palavras fosse comum a ambos os casos, não se poderia constatar uma conexão terminológica firme. Mas a força do argumento está na existência de dois termos em comum. A lém disso, a ligação entre a supraconsciência do Um e a mística da alma se torna ainda mais evidente em VI, 7, 40, onde Plotino diz: "que não é necessário intelecção no que diz respeito a ele $(o \mathrm{Um})$, saberiam os que a ele se ligaram"49. Ora, os que experimentaram o Um só poderiam saber em que consiste sua consciência se a experimentaram. Assim, devemos concluir que tal experiência não éa contemplação de al go exterior, mas a experiência da supraconsciência e do supraconhecimento próprios ao A bsoluto: durante a visão mística, a alma é marcada por uma ausência total de alteridade e por uma identidade pura que é como que o "pensamento" do Um. ${ }^{50}$

\section{Identidade}

Vimos que, durante a contemplação mística, a alma se torna semel hante ao Um, suprimindo toda alteridade, e experimenta sua própria vida interior, que é como que uma intuição e um toque. Nessa contemplação, não existe um objeto, seja exterior, como no caso do conhecimento sensível, seja interior, como no caso da mística intelectual:

E este é um discurso audacioso. Então, o que vê nem vê, nem distingue, nem imagina dois, mas, como se viesse a ser outro, e não ele mesmo, nem de si mesmo, pertence àquele lugar, e, vindo a ser daquele, é um, como um centro que coincide com um centro. ${ }^{51}$

Mas, até onde vai essa identidade? A alma se torna tão semelhante ao Um, a ponto de transformar-se nele? Essa questão, que mereceu a atenção de

${ }^{48} \mathrm{O}$ termo era originariamente empregado pelos epicuristas, obviamente em um sentido não místico. A esse respeito, ver O'DALY em Plotinus' Philosophy of the Self, Shannon, 1973, p. 93-94.

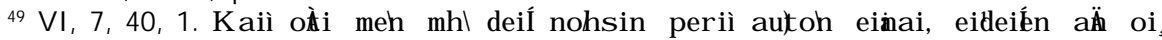
prosay amenoi tou= toioutou.

${ }^{50}$ Essa conclusão causa tanto estranhamento que até mesmo O’Daly, um dos únicos comentadores a enunciá-la, o fez em uma frase interrogativa (em Plotinus' Philosophy of the Self, p. 94). No entanto, essa parece ser a conclusão a qual nos levam os textos. ${ }^{51} \mathrm{VI}, 9,10,10-17$. tol mhrol meh ol $\mid$ ogoj. Tote meh ouß ouÃe or \#= oublel diakrinei ol ofwbra oudel fantaketai dub, a)l' oiân ẫloj genomenoj kaiì ouk autoj ould aufou=suntel eil ekeil kakeigou genomenoj eÁ e\$tin wöper kehtr\% kehtron sunayaj. 
quase todos os intérpretes plotinianos que se ocuparam da experiência mística ${ }^{52}$, recebeu sua formulação clássica no Plotinus de Rist ${ }^{53}$, que lhe aplicou categorias retiradas do livro de Zaehner, Mysticism, Sacred and Profane. Zaehner distinguiu quatro espécies de misticismo: a experiência pantésta, de identificação da alma com o mundo natural; a mística que isola a alma individual da natureza, mediante a ascese; o misticismo monista, no qual a alma individual é absolutamente idêntica ao poder que rege o universo; o misticismo tésta, no qual a al ma se une a um deus transcendente, que não pode, no entanto, ser identificado com ela.

Rist exclui rapidamente a segunda possibilidade e, em seguida, também a possibilidade pantésta, pois, nas Enéadas, o Um é, ao mesmo tempo que imanente, também transcendente ao mundo. A lém disso, existem passagens nas quais Plotino afirma claramente que o Um não é todas as coisas ${ }^{54}$. No restante do texto, ele se dedica a argumentar pela opção teísta em oposição ao monismo. Outros autores, em especial Mamo, reagiram contra essa posição, defendendo alguma espécie de monismo plotiniano ${ }^{55}$.

Não entrarei no mérito da discussão, pois vejo nela um erro de base: não creio que as categorias do teísmo e do monismo sejam adequadas para a experiência de Plotino. ${ }^{56} \mathrm{~A}$ mística de Plotino é, de certa forma, as duas coisas, pois o Um é, ao mesmo tempo, imanente e transcendente. ${ }^{57}$

É por isso que encontramos passagens das Enéadas que poderiam corrobar a posição teísta, como VI, 7, 35, onde a experiência do Um é apresentada como a contemplação do Intel ecto amante - que é semelhante ao Um, mas não idêntico a ele -, ao lado de textos como VI, 9, 3, 10-13 e VI, 9, 10, 1017 , que afirmam não ser possível distinguir um objeto ou conceber uma dualidade na experiência mística do Um.

\footnotetext{
52 Ver, por exemplo, ARNOU, R. Le Désir de Dieu, p. 250-251; RIST, J. Plotino, Genova: II Melangolo, 1995, p. 278-300; BUSSANICH, J. The One and Its Relations to the Intellect, p. 180-193; MEIJ ER, P. Plotinus on the Good or the One, p. 307-310. 53 RIST, Plotino, p. 278-330.

${ }^{54}$ Rist cita $V, 5,12,47$. Mas é Arnou que apresentou a refutação definitiva e exaustiva da interpretação panteísta de Plotino. A esse respeito, ver Le Désir de Dieu, p. 157191.

55 Rist, por sua vez, respondeu ao texto de Mamo em Back to the Mysticism of Plotinus.

${ }^{56}$ Aliás, suspeito dessas categorias também com relação ao misticismo hindu, que os intérpretes plotinianos não hesitam em classificar de monista. A esse respeito, ver GUÉNON, R. Introduction Générale à l'Étude dês Doctrines Hindoues. Paris: Editions Guy Trédaniel, p. 1997.

${ }^{57}$ Ver Arnou, op. cit. A imanência e transcendência do Um é bem expressa no início de V, 2: "O Um é todas as coisas e nenhuma delas": tol eÁ pahta kai ouldel eÀ.
} 
No fundo, a dificuldade do tema ea multiplicidade de abordagens possíveis é decorrência da própria transcendência e inefabilidade da experiência: quando se está acima do mundo das formas, toda atribuição e categoria é apenas metafórica. Não há outro modo de ser preciso, neste caso, além do silêncio.

Uma vez cientes das dificuldades e dos perigos de se dizer que o misticismo plotiniano seja monista ou teísta, podemos investigar o que as Enéadas têm a dizer sobre a identidade entre a alma e o Um durante a união.

Várias passagens mostram que se trata de uma união real: al ém de VI, 9, 3, 10-13, onde é dito que o inteligido não é outro, e de VI, 9, 10, 14-17, onde Plotino afirma não ser possível distinguir a alma e o Um nessa ocasião, outros textos também ilustram esse ponto. Por exemplo:

Certamente, já que não eram dois, mas eram um o que vê junto do que era visto - de modo que não era visto, mas unido ${ }^{58}$.

Pois não há nada entre eles e não são mais dois, mas ambos são um. Nem seria possível distingui-los, enquanto ele está presente ${ }^{59}$.

A lém disso, se a alma é capaz de suprimir toda sua al teridade e se, quando faz isso, ela atinge uma supraconsciência que é como a supraconsciência do Um, parece que a alma atinge a unidade com ele. Pois, se não fosse o caso, ela então seria diferente do Um de al gum modo: mas como é possível ser diferente quando não existe alteridade?

Por outro lado, refletindo um pouco sobre a natureza dessa identidade, fica evidente o seu limite. Pois a alma suprime a alteridade aquietando as suas potências. Quando ela é una, nada se move nela, nem as paixões, nem os discursos, nem as intelecções ${ }^{60}$. É nessa quietude absoluta que a alma se assemelha ao Um. No entanto, ao contrário do princípio supremo, que é eternamente identidade e quietude pura, a alma pode, a qualquer momento, voltar à esfera da alteridade ${ }^{61}$. $\mathrm{E}$, de fato, isso inevitavel mente acontece, ao menos enquanto a alma está encarnada. ${ }^{62}$ Assim, durante a experiência mística, a alma possui identidade com o Um e ambos são um só. Mas a alma é, potencialmente, ainda uma alma.

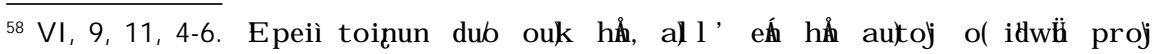
tol ewramehon, wj ä̈ mhl ewramehon, all' hhwmehon.

$59 \mathrm{VI}, 7,34,12-14$. Kaiì metacul gar oudeh oud' eÃi dub, all' eÁ añf w: ou) gar ä̈ diakrinaij eñi, ềj paresti.

$60 \mathrm{VI}, 9,11,15$.

${ }^{61}$ Não se deve pensar, a partir daí, que na filosofia de Plotino a alma seja mais que o Um nesse aspecto. Afinal, a capacidade de cair na multiplicidade é a capacidade de entrar em uma esfera inferior da existência e, portanto, não há nisso nenhuma vantagem.
} 
Com A rmstrong e contra M eijer, creio que a expressão eె a đifi w, "ambos são um" de VI, 7, 34, 14, ecoa o eß \& in ađifi w kai duQ, "ambos são um e dois", de IV , 4, 2, 29, aplicada à mística intelectual. Pois, como vimos nessa passagem ${ }^{63}$, no que diz respeito à ligação da alma com o Intelecto durante essa experiência, Plotino também fala de união, também diz que ambos são uma só coisa. A lém disso, declara que não existe nada entre eles. Mas afirma também que, apesar disso, a alma não deixa de ser alma e que, ainda que, nesse momento, os dois sejam uma só coisa, são ainda dois. Não existe uma passagem das Enéadas que diga explicitamente as mesmas coisas sobre a união da alma com o Um, o que daria uma resposta definitiva à presente questão, mas não é inverossímil, a partir do que foi visto aqui, que se trate de um caso análogo.

Endereço do Autor:

Rua Musas, 250

30360-660 Belo Horizonte - MG

geraldosantos@yahoo.com.br

${ }^{62} \mathrm{VI}, 9,10$.
63 p. 9. 